\title{
ANÁLISE MICROCLIMÁTICA NO INTERIOR E FORA DAS FLORESTAS ESTACIONAIS SEMIDECIDUAIS NA ÁREA DA BACIA DA USINA HIDRELÉTRICA DE CAÇU-GO
}

\author{
Andreia Medeiros de Lima ${ }^{1}$ \\ Zilda de Fátima Mariano
}

Resumo: $O$ presente artigo analisou o microclima em pontos no interior das florestas estacionais semideciduais (FES) e em pontos fora das FES, em áreas de pastagens, na bacia da Usina Hidrelétrica de Caçu (UHE-Caçu), situada nos municípios de Caçu e Cachoeira AltaGO. Os dados de temperatura e umidade relativa do ar foram obtidos dos termohigrômetros, na escala diária, no período de setembro de 2011 a setembro 2012. A metodologia utilizada foi a escala microclimática baseada em Geiger (1961) e Serafini Júnior et al (2011) considerando um ponto no interior da FES com melhor estado de conservação em relação aos aspectos: a) variabilidade estrutural, ou seja, o tamanho das espécies e os estágios de idade (mudas até os senescentes) e b) preservação pela não infestação de lianas, sinais de cortes de espécies e pisoteio do gado, a altura dos indivíduos e maior diâmetro a altura do peito (DAP). Os pontos no interior das FES em melhor estado de preservação apresentaram as menores temperaturas máximas absolutas 36,7 ㄷ C no $P 1$ e 37,6 ㄷ no $P 2$, já os pontos fora das FES, nas áreas de pastagens apresentaram as maiores temperaturas máximas absolutas 42,8 ㅇ C no $P 7$ e 42,6 ㅇ C no $P 5$, esta diferença no microclima ocorreu principalmente devido a estrutura da vegetação nas FES e ao uso e ocupação do solo.

Palavras-Chave: Microclima; Variabilidade; Cerrado.

Abstract: This article analyzed the microclimate in points inside the semideciduous forests (FES) and points out the FES in pasture areas in the basin Caçu Hydropower Plant (UHE Caçu), located in the municipalities of Cachoeira Alta and Caçu GO. The data of temperature and relative humidity were obtained from termohigrômetros in daily scale, from September 2011 to September 2012. The methodology used was based on the scale microclimatic Geiger (1961) and Junior Serafini et al (2011) considering a point inside the FES with the best condition regarding aspects: a) structural variability, that is, the size of the species and the stages of age (seedlings until senescent) and b) preserving the non liana infestation, signs of cuts and trampling of livestock species, the plant height and larger diameter at breast height (DAP). Points within the FES in a better state of preservation showed the lowest absolute maximum temperatures $36.7^{\circ} \mathrm{C}$ in $\mathrm{P} 1$ and $37.6{ }^{\circ} \mathrm{C}$ in $\mathrm{P} 2$, since the points outside the FES, the pastures had the highest absolute maximum temperatures $42.8{ }^{\circ} \mathrm{C}$ in $P 7$ and $P 5$ at $42.6{ }^{\circ} \mathrm{C}$, this difference in microclimate is mainly due to vegetation structure in the FES and the use and occupation of land.

Keyword: Microclimate; Variability; Cerrado.

\footnotetext{
${ }^{1}$ Graduada em Biologia, mestrado em geografia área de concentração análise ambiental, Professora PIV Secretária da Educação do Estado de Goiás. E-mail: medeiroslima.andreia@gmail.com

${ }^{2}$ Professora Adjunta da Universidade Federal de Goiás, Graduada em Geografia com doutorado em Geografia Física área de concentração climatologia. E-mail: zildadeefatimamariano@gmail.com
} 


\section{INTRODUÇÃO}

O desenvolvimento de pesquisas na área da climatologia geográfica nas diferentes escalas do clima e o enfoque para as escalas inferiores do clima são fundamentais para a compreensão da interação entre os elementos climáticos e o meio natural ou antropizado, surgindo assim a necessidade da coleta de dados em pontos específicos para entender as particularidades do microclima em cada ambiente.

No microclima das florestas é típico temperaturas amenas e umidade relativa do ar mais alta em comparação a ambientes descobertos de vegetação ou com solo exposto e, também, apresentar maior variabilidade climática dependendo da estrutura da floresta.

Com a implantação da UHE na bacia de Caçu, em março de 2010, esta sofreu modificações com o aumento da área ocupada por água, perda de parte da mata ciliar, pois entre os principais problemas encontrados na bacia hidrográfica está, o avanço no desmatamento, em razão da expansão de monoculturas e pecuária, ameaçando ecossistemas e fragmentos de vegetação remanescentes, (ESTUDO INTEGRADO DE BACIAS HIDROGRÁFICAS DO SUDOESTE GOIANO -EIBHSG, 2005).

Com a coleta de dados climáticos para o projeto Pró-Centro-Oeste, "Análise do impacto da ação antrópica nas características hidrossedimentológica/limnológica da bacia do Rio ClaroGO", a pesquisa realizou-se na bacia da Usina Hidrelétrica Caçu (UHE-Caçu), nos municípios de Caçu e Cachoeira Alta-GO, com os dados diários, máximos e mínimos absolutos da temperatura e umidade relativa do ar, no interior das florestas estacionais semideciduais (FES) e fora das FES, em áreas de pastagens, no período de setembro de 2011 a setembro de 2012, na escala microclimática.

\section{MATERIAIS E MÉTODOS}

\section{Caracterização da Área de Estudo}

Segundo Moragas (2005), a bacia da Usina Hidrelétrica Caçu (UHE-Caçu), pertence à bacia do Rio Claro, com área de $13.500 \mathrm{~km}^{2}$, situada no estado de Goiás, na porção sudoeste, abrangendo dez municípios: Jataí, Rio Verde, Mineiros, Caiapônia, Perolândia, Aparecida do Rio Doce, Cachoeira Alta, Caçu, São Simão e Paranaiguara, pertencentes ás microrregiões do Sudoeste de Goiás e Quirinopólis, localizados na mesorregião do Sul Goiano. 
$\bar{O}$ rio Claro é um dos principais tributários do rio Paranaíba, divisor dos estados de Goiás e

Minas Gerais e possui grande potencial hidrelétrico, com Pequenas Centrais HidrelétricasPCH's, a de Jataí e Sertãozinho e Usinas Hidrelétricas-UHE's, a Ari Franco, Pontal, Caçu , Barra dos Coqueiros, Itaguaçu e Foz do Rio Claro (EIBHSG, 2005).

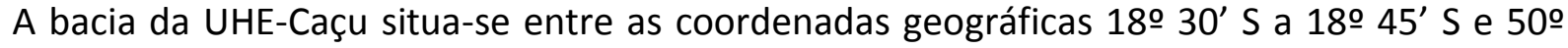
55' W a 51 10' W, no baixo curso do Rio Claro, na mesorregião do Sul Goiano e a microrregião de Quirinópolis, com o principal uso da terra em pecuária, seguido do cultivo da cana-de-açúcar e a silvicultura. (Figura 1).

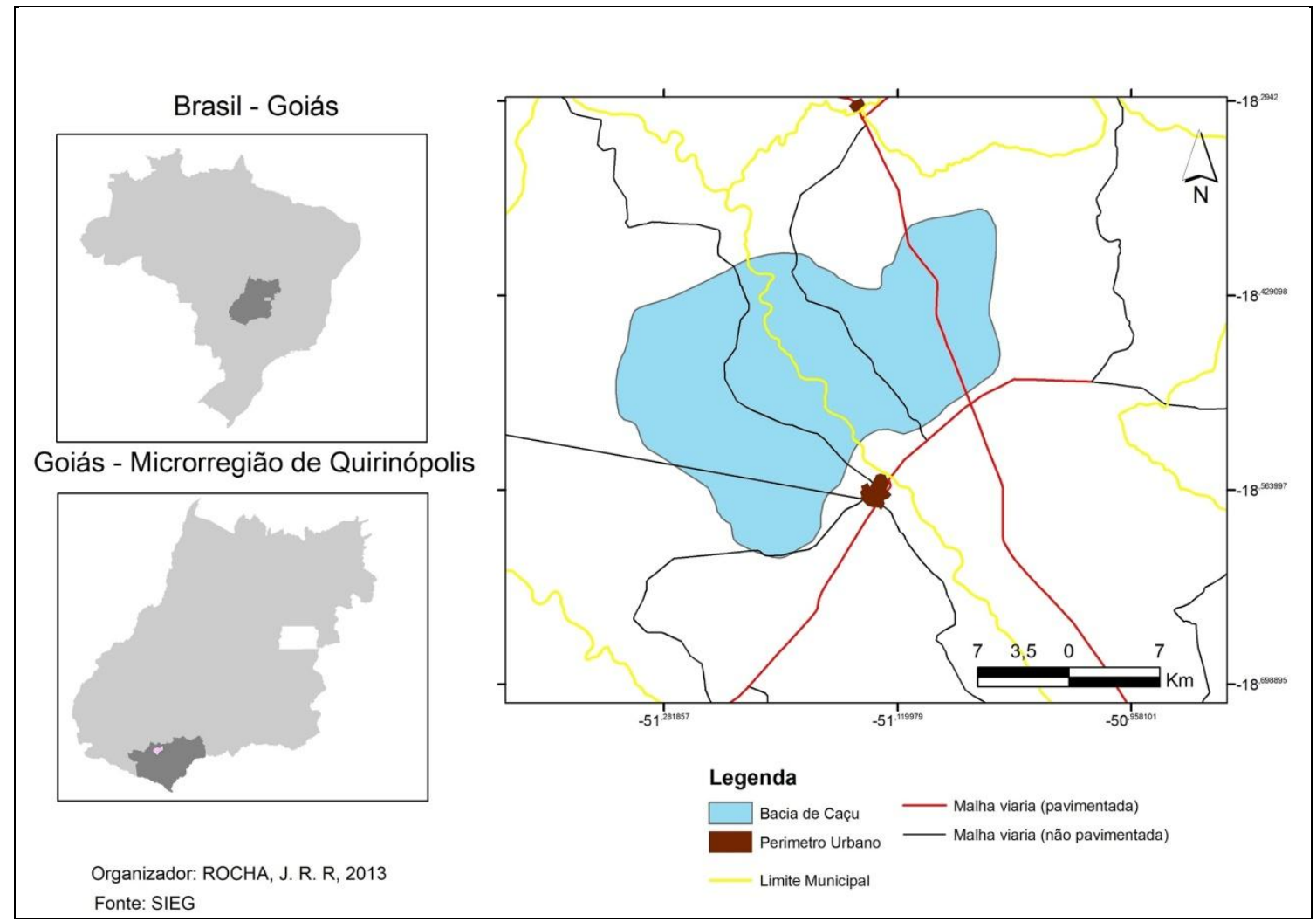

Figura 01 - Localização da área de estudo, Bacia da UHE-Caçu/GO. Org.: Lima; Mariano (2013).

Na bacia da UHE-Caçu os rios encontram-se em segmentos alternados, protegidos por mata ciliar e fragmentados pela ampliação de pastagens ou lavouras e manchas de formações naturais em porte de cerradão. No entanto, os principais impactos ambientais encontrados resultam da prática da pecuária, como nos locais de dessedentação animal, pois há contaminação da água, erosões e voçorocas; avanço dos desmatamentos, devido ao aumento de áreas de monocultura e pecuária, sendo este a maior ameaça aos ecossistemas e fragmentos de vegetação remanescentes (EIBHSG, 2005). 
A vegetação predominante é do bioma Cerrado, segundo os critérios de classificação fitofisionômica de Ribeiro e Walter (2008), encontrado em diferentes formas, como: as formações florestais (mata ciliar, mata de galeria, mata seca (florestas estacionais semideciduais) e cerradão), as formações savânicas (cerrado sentido restrito, o parque cerrado, o palmeiral e a vereda) e as formações campestres (campo sujo e o campo limpo). As florestas estacionais semideciduais (FES) estão incluídas dentro das formações florestais do Cerrado. Ribeiro e Walter (2008) as denominam de mata seca semidecídua, pois ocorrem em terrenos bem drenados e solos de alta fertilidade; na época chuvosa, o dossel chega a formar uma cobertura de 70 a 95\%, sendo possível visibilizar a presença equilibrada de espécies sempre verdes e caducifólias, ou seja, alguns indivíduos perdem suas folhas no período seco, característica semidecídua.

Nascimento et al (2004) apontam que as florestas estacionais do Brasil Central estão sendo convertidas rapidamente em áreas agrícolas e de pastagens. Pivello (2005, grifo do autor) associa o alto grau de fragmentação da vegetação do Cerrado "a ilhas", cercada por pastos e monoculturas, tais como a soja, a cana-de-açúcar e outras espécies fornecedoras de madeira e celulose, fato esse considerado pelo autor como um agravante à perda de biodiversidade.

De acordo com o SIEG (2011), baseado na classificação de solos da Embrapa (2009), a bacia da UHE-Caçu possui sete tipos de solos: Latossolo Vermelho Distrófico; Latossolo VermelhoAmarelo Distrófico; Latossolo Vermelho Perférrico; Argissolo Vermelho-Amarelo Distrófico; Neossolo Quartzarênico Órtico; Nitossolo Vermelho Eutrófico e Cambissolo Háplico Tb Distrófico.

O uso da terra em 2011 foi de 68\% pastagens, 19\% de vegetação nativa (formações florestais, savânicas e campestres), $8 \%$ de água, 3,4\% solo exposto, 1,3\% cultura e 0,3\% urbano.

O clima da área caracteriza-se por duas estações bem definidas, sendo uma estação chuvosa e uma estação seca, com precipitação pluvial anual entre 1400 e 1500 mm, o que acaba tendo influência direta na vegetação por meio do solo, segundo Novelis (2005).

Em estudo realizado por Mariano (2005) na microrregião sudoeste de GO, onde se situa a bacia, a variabilidade das chuvas mostrou uma concentração no sul e norte e diminuição nordeste para leste na microrregião, no período de 1978/2003. 
Segundo Silva et al (2008), a precipitação média anual na bacia da UHE- Caçu varia entre 1400 a 1600 mm; a estação seca inicia-se entre abril e maio e vai até os meses de setembro a outubro, e a temperatura média anual oscila entre 22,0 e $23,0^{\circ} \mathrm{C}$.

\section{A escala de estudo}

Para realização do estudo foi fundamental determinar a escala climática abordada, pois a escala define a dimensão espacial e temporal; utilizamos a escala microclimática. Segundo Nunes (1998), a escala não determina apenas a área (espaço) e período (tempo), mas também as técnicas e os métodos a serem utilizados a fim de se alcançar os objetivos da pesquisa.

Mendonça e Danni-Oliveira (2007) consideram que o microclima é determinado pelo uso do terreno, geralmente em áreas com extensão pequena, como por exemplo, o clima de uma sala de aula, de uma rua ou um bosque.

Geiger (1961, p.5) aponta que próximo ao solo ocorrem diferenças nos elementos climáticos e, também horizontalmente, em áreas reduzidas devido às características do solo, umidade, diferenças mínimas do relevo e o tipo de vegetação que recobre o terreno, assim define "como sendo o estudo da camada de ar junto ao solo, com altura convencionada de $2 \mathrm{~m}$ ". Pardé (1978) observou que dentro da floresta ocorre um microclima distinto daquele de um terreno descoberto, o qual, por sua vez, condiciona os processos de desenvolvimento das plantas, florescimento, frutificação, germinação, crescimento e produção e esse papel modificador exercido pela floresta varia de acordo com as espécies, com as características da população, como altura e densidade, com a estação do ano e com a região em que se encontram.

Pereira et al (2002) consideram que o fator principal condicionante do microclima é a cobertura do terreno, o que quer dizer que cada tipo de terreno, por possuir uma variedade de cobertura, influenciará o microclima.

Galvani e Lima (2010) ressaltam que a vegetação é um dos principais agentes controladores do microclima, já que está ligada ao uso e/ou cobertura do solo, verificando que a estrutura fisionômica do mangue mostrou influência direta na variação da precipitação, radiação solar e velocidade do vento abaixo do dossel, formando um microclima distinto daquele sem vegetação. 
Sobre os estudos na escala microclimática, considerando áreas com cobertura vegetal, destacamos as pesquisas de Hernandes (2001), Pezzopane (2001), Monteiro e Azevedo (2005), Armani (2009), Lima (2009), Galvani e Lima (2010) e Lopes (2011).

\section{Procedimento de análise}

Os dados diários máximos e mínimos da temperatura e umidade relativa do ar foram obtidos por meio dos aparelhos termohigrômetros (Data Logger, modelo HT-4000), programados para registrar os dados em intervalo de 30 minutos, no período de setembro de 2011 a setembro de 2012, na escala horária, diária e mensal, (Figura 2, Figuras 3A e 3B).

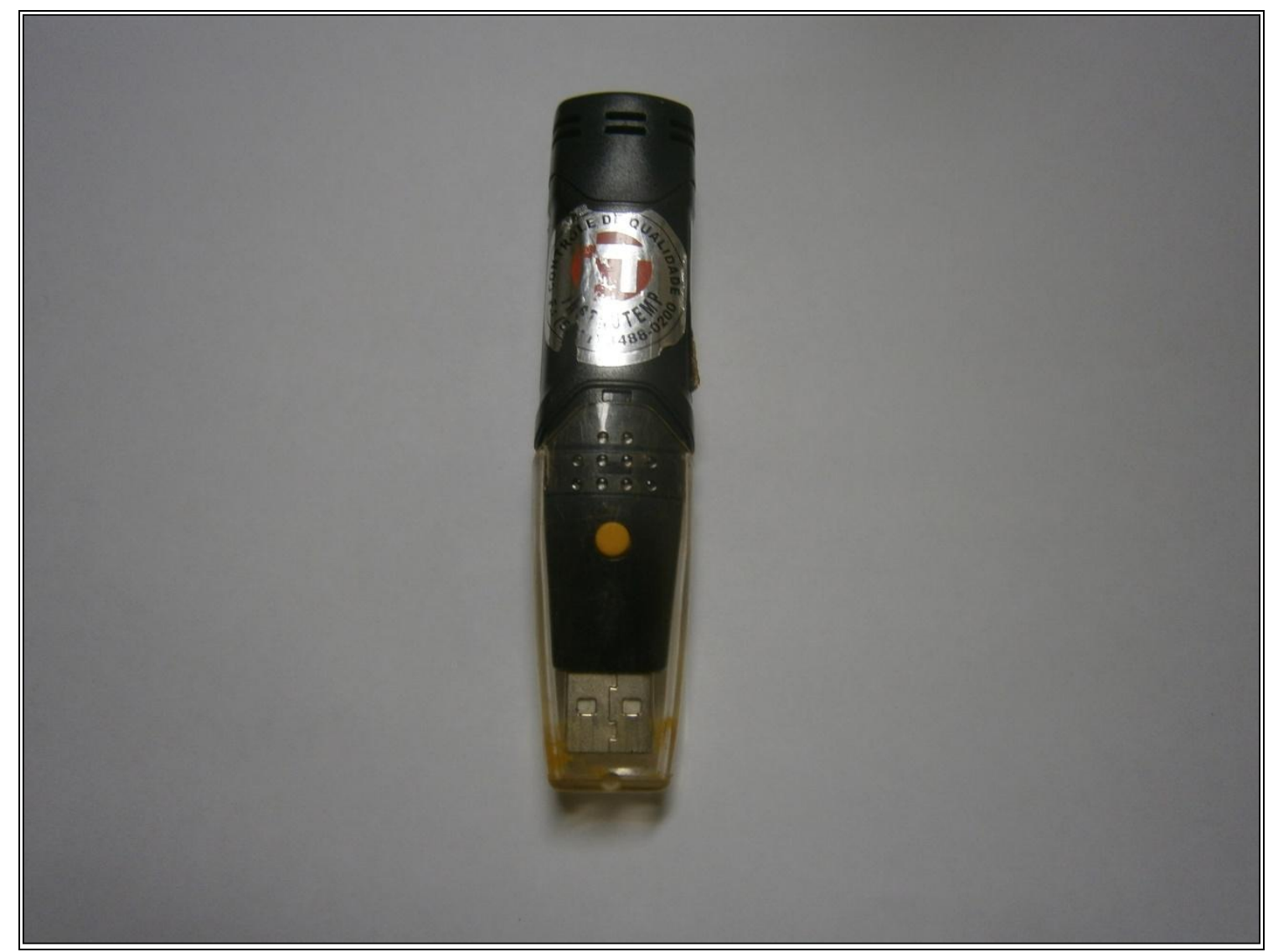

Figura 2- Termohigrômetro, aparelho coletor de temperatura e umidade do ar, na bacia da Usina Hidrelétrica Caçu (UHE-Caçu)

Foto: Lima (2013).

Esses termohigrômetros foram instalados em quatro pontos (P1 a P4) no interior das FES e quatro (P5 a P8) fora das FES, nas fazendas, em áreas de pastagens (Quadro 1 e Figura 4). 


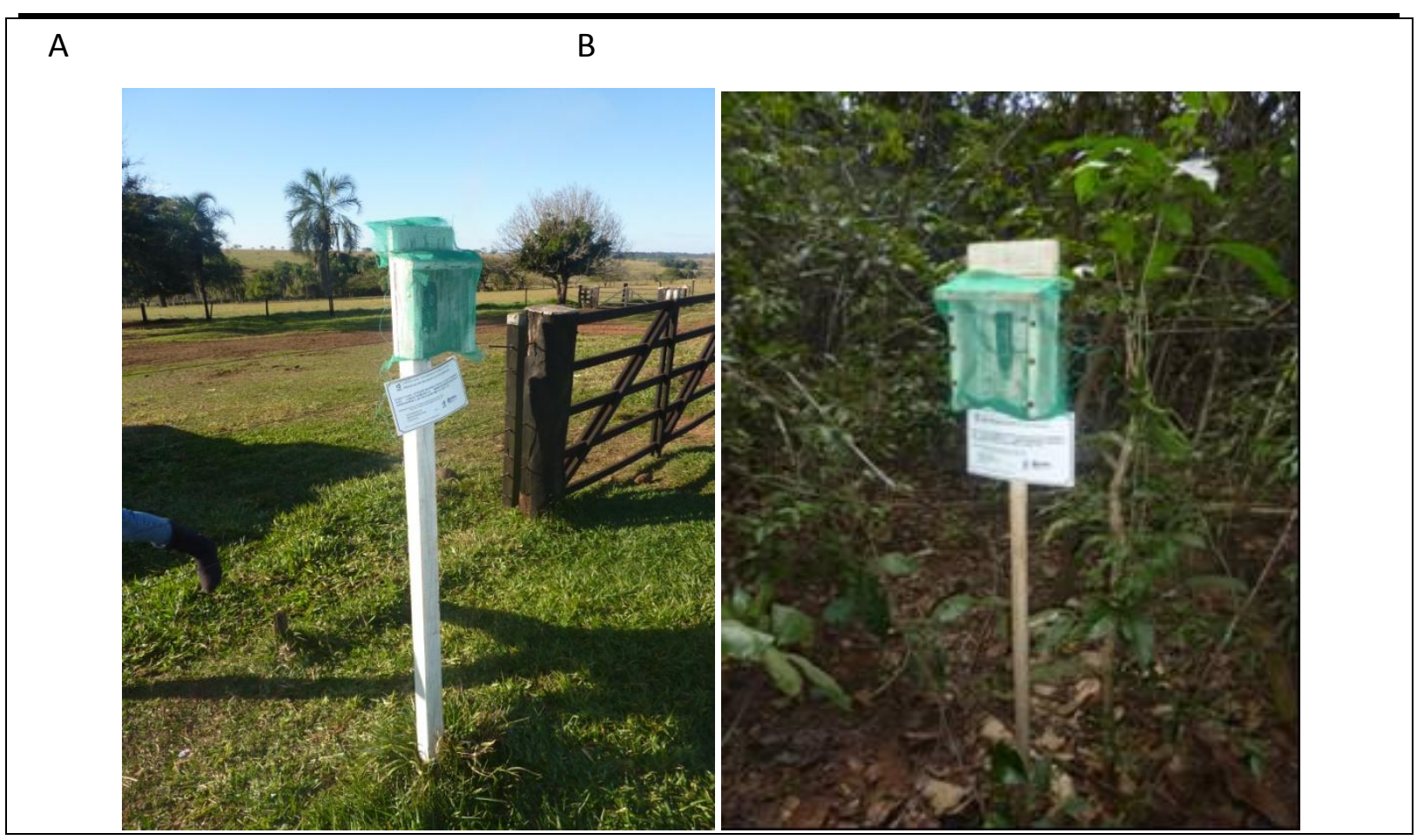

Figura 3 A e B - Termohigrômetros instalados fora das FES e no interior das FES Fotos: Lima (2013).

Quadro 1- Localização dos pontos de coleta, na área de estudo

\begin{tabular}{|c|c|c|c|c|c|}
\hline Ponto & Bacia da UHE & Pontos & $\begin{array}{c}\text { Coordenada m } \\
\text { E }\end{array}$ & $\begin{array}{c}\text { Coordenada m } \\
\text { N }\end{array}$ & Altitude \\
\hline P1 & Caçu & FES Ribeirão dos Paula I* & 482541 & 7957237 & $498 \mathrm{~m}$ \\
\hline P2 & Caçu & FES Caçu* & 482798 & 7952037 & $436 \mathrm{~m}$ \\
\hline P3 & Caçu & FES Caçada* & 476836 & 7961745 & $528 \mathrm{~m}$ \\
\hline P4 & Caçu & FES Rib. dos Paula III* & 485291 & 7952939 & $483 \mathrm{~m}$ \\
\hline P5 & Caçu & Fazenda Gabriela & 490898 & 7933798 & $452 \mathrm{~m}$ \\
\hline P6 & Caçu & Fazenda Caçada & 476386 & 7961745 & $497 \mathrm{~m}$ \\
\hline P7 & Caçu & $\begin{array}{c}\text { Fazenda Ribeirão dos Paula } \\
\text { I }\end{array}$ & 481584 & 7958469 & $489 \mathrm{~m}$ \\
\hline P8 & Caçu & $\begin{array}{c}\text { Fazenda Ribeirão dos Paula } \\
\text { III }\end{array}$ & 485416 & 7952669 & $476 \mathrm{~m}$ \\
\hline
\end{tabular}

Fuso 22, Meridiano 51으, Watum WGS 84

* Ponto instalado no interior das FES

Org.: Lima; Mariano (2013)

Para a análise na escala microclimática, utilizamos duas metodologias: o conceito de microclima de Geiger (1961, p.5) "[...] clima de áreas muito reduzidas [...]" "[...] a camada de ar inferior à altura convencionada de cerca de $2 \mathrm{~m}[\ldots]$ ]" e de Serafini Júnior et al $(2011$, p.5), que partiu de um cenário de referência (o qual consideraremos ponto de referência) em relação aos demais e definiram que quanto maior a diferença de temperatura e umidade do ar entre o ponto de referência e os demais pontos, "[...] maior é a modificação das características desses pontos em relação ao primeiro". 


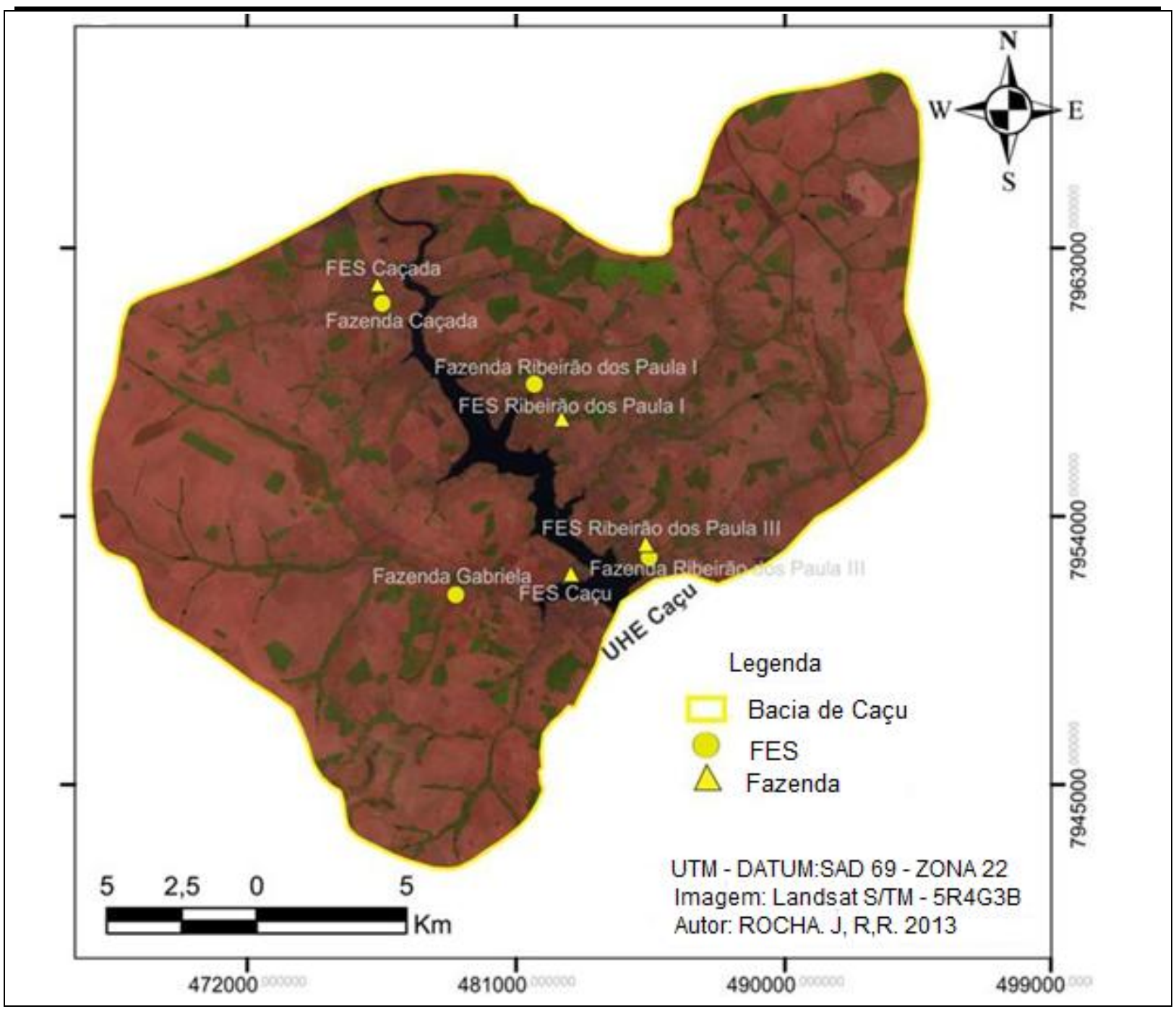

Figura 4 - Localização dos pontos de coleta na bacia das UHE de Caçu-GO.

Org.: Lima (2013).

Para a definição dos pontos no interior das FES foram realizados o estudo visual e o levantamento do número de espécies em uma parcela de $20 \times 20 \mathrm{~m}$, para identificar o estado de conservação baseado em dois aspectos: a) variabilidade estrutural, ou seja, o tamanho das espécies e os estágios de idade (mudas até os senescentes) e b) preservação pela não infestação de lianas, sinais de cortes de espécies e pisoteio do gado. Assim a FES Ribeirão dos Paula I (P1) foi escolhida como referência, devido à altura dos indivíduos e maior diâmetro à altura do peito (DAP) na parcela (Figura 5 e Eq. 01), sem infestação de lianas e sinais de cortes e pisoteio do gado.

A escolha da parcela obedeceu como critério à localização do ponto de coleta dos dados de temperatura e umidade do ar; assim, estabelecemos, então, única parcela em torno do ponto de $20 \mathrm{~m} \times 20 \mathrm{~m}\left(400 \mathrm{~m}^{2}\right.$ ou 0,04 ha) para análise da avaliação da estrutura da vegetação nas FES, onde foram coletados: perímetro altura do peito (PAP), convencionado à 
altura de 1,3 $\mathrm{m}$ do solo e altura dos indivíduos vivos com PAP igual ou superior a $30 \mathrm{~cm}$. Através da divisão do PAP pelo valor de $\pi(3,1416)$, obtém-se o diâmetro altura do peito (DAP), em cm.

Figura 5 - Representação da parcela de $400 \mathrm{~m}^{2}$, utilizada para coleta dos dados da estrutura da vegetação Org.: Lima (2013)

O método fitossociológico utilizado foi de Felfili e Rezende (2003, p.7), considerando o parâmetro densidade absoluta (DA), que defini "o número de indivíduos (n) de uma determinada espécie na área". Como as espécies não foram identificadas, consideramos o número total de indivíduos, calculado pela equação 1:

$$
\mathbf{D A}=\frac{\mathbf{n}}{\text { área }}
$$

onde: $\mathrm{DA}=$ densidade absoluta; $\mathrm{n}=$ número de indivíduos; área = hectares (ha).

Os pontos fora das FES, localizados nas fazendas, em áreas de pastagens foram escolhidos devido à proximidade dos pontos no interior das FES.

Após a coleta dos dados selecionamos os meses que apresentaram os valores máximos e mínimos absolutos da temperatura e umidade relativa do ar, sendo que setembro apresentou as maiores temperaturas máximas absolutas, no horário das 15 horas, e julho as menores temperaturas mínimas absolutas às 7 horas e a umidade relativa máxima absoluta foi em janeiro, às 5 horas, e setembro as mínimas absolutas, às $15 \mathrm{~h}$. 


\section{RESULTADOS E DISCUSSÃO}

Variação dos parâmetros fitossociológicos das FES, na bacia da Usina Hidrelétrica

\section{Caçu (UHE-Caçu)}

O número de indivíduos na parcela analisada em cada FES foi de 23 indivíduos na P2 e P3, 20 indivíduos na P1 e na P4, 16 indivíduos. A altura média foi de 10,1 m na P3, 9,5 m na P1, 8,8 m na P2 e de 8,3 m na P4 (Tabela 1).

A média do diâmetro à altura do peito foi de $22,2 \mathrm{~cm}$ na $P 3,19,6 \mathrm{~cm}$ na $P 1,17,5 \mathrm{~cm}$ na $\mathrm{P} 2 \mathrm{e}$ de $17 \mathrm{~cm}$ na P4 e a densidade absoluta foi maior na P2 e P3 com 575 indivíduos/ha, na P1 com 500 indivíduos/ha e na P4 com 375 indivíduos/ha (Tabela 1).

A FES P3 apresentou a maior altura média, maior diâmetro à altura do peito (DAP), maior número de indivíduos e maior densidade absoluta dos indivíduos, porém apresentou sinais de corte de alguns indivíduos.

Os menores parâmetros foram encontrados na FES P4 e com infestação por lianas, sinais de pisoteio de gado, corte de árvores, resquícios de queimadas e trilhas

Considerando os parâmetros fitossociológicos descritos e os critérios estabelecidos para conservação, a FES P1 apresentou melhor estado, pois não tinha evidências de cortes, pisoteio do gado ou queimadas.

Tabela 1 - Números dos indivíduos, altura média, média do diâmetro à altura do peito (DAP) e densidade
absoluta (DA) referente aos indivíduos vivos das FES
\begin{tabular}{c|c|c|c|c} 
Ponto & $\begin{array}{c}\text { Número de } \\
\text { indivíduos }\end{array}$ & $\begin{array}{c}\text { DAP média } \\
\text { (cm) }\end{array}$ & $\begin{array}{c}\text { Altura } \\
\text { média (m) }\end{array}$ & $\begin{array}{c}\text { Densidade Absoluta } \\
\text { (DA) }\end{array}$ \\
\hline FES Rib.dos Paula I (P1) & 20 & 19,6 & $9,5 \mathrm{~m}$ & 500 indivíduos/ha \\
FES Caçada (P2) & 23 & 17,5 & $8,8 \mathrm{~m}$ & 575 indivíduos/ha \\
FES Caçu (P3) & 23 & 22,2 & $10,1 \mathrm{~m}$ & 575 indivíduos/ha \\
FES Rib.dos Paula III (P4) & 16 & 17 & $8,3 \mathrm{~m}$ & 375 indivíduos/ha \\
\hline
\end{tabular}

Fonte: Lima; Mariano (2013)

\section{Variação mensal das temperaturas máximas e mínimas absolutas}

A variação da temperatura do ar sofre influência do relevo. Na bacia da Usina Hidrelétrica Caçu (UHE-Caçu) as temperaturas do ar máximas ocorrem na exposição a norte, noroeste e oeste, enquanto os pontos localizados nas vertentes sul, sudeste e leste recebem menos insolação. 
Os maiores valores de temperaturas máximas foram registrados no mês de setembro, quando o ponto de referência (P1) registrou a temperatura máxima absoluta de $36,7^{\circ} \mathrm{C}$, os pontos no interior das FES (P2, P3 e P4), a maior temperatura máxima absoluta foi no P4, com 40,0 ㄷ, pois a FES apresentou sinais de pisoteio do gado, muitas lianas e a exposição das vertentes a leste, com maior insolação, e o ponto $\mathrm{P} 2$ registrou $37,6{ }^{\circ} \mathrm{C}$, a menor temperatura máxima absoluta, devido ao melhor estado de conservação da FES e exposição da vertente a sudeste, com menor insolação, (Tabela 2 e Figura 6).

Verificou-se que as FES (P1 e P2) apresentaram melhor estado de conservação e registraram temperaturas máximas absolutas menores, 36,7 ㅇ C e 37,9 으, respectivamente, e embora a FES P3 tenha apresentado maior número de indivíduos e maior DAP em relação às demais FES, esta também apresentou interferências antrópicas e está mais próxima do reservatório da UHE de Caçu, o que interferiu no microclima.

As FES (P3 e P4) que apresentaram maiores perturbações antrópicas (entrada do gado e trilhas) e pequeno porte arbóreo, registraram as maiores temperaturas máximas absolutas,

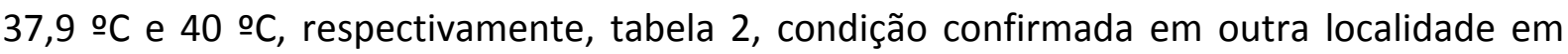
estudo realizado por Serafini Júnior et al (2011), no Parque Embu - Mirim (SP),

As condições de caducifólia, ou seja, perda das folhas, que se inicia no período de estiagem, entre abril e setembro, período que o dossel vegetal está mais aberto, recebendo maior quantidade de radiação, influência no microclima desses pontos, confirmado por Pezzopane (2001), que constatou diferenças microclimáticas expressivas, no mês de setembro em relação aos outros meses, em estudo realizado em Viçosa-MG.

Nos pontos fora das FES (P5, P6, P7 e P8), nas áreas de pastagens, foram registradas as maiores temperaturas máximas absolutas de 42,$6 ; 40,9 ; 42,8 ; 40,8{ }^{\circ} \mathrm{C}$, respectivamente, em relação ao ponto de referência $\mathrm{P} 1\left(36,7^{\circ} \mathrm{C}\right)$, com uma diferença térmica de $6,1^{\circ} \mathrm{C}$ entre o P1 e o P7, Tabela 2 e Figura 6.

Tabela 2 - Temperatura máxima absoluta $\left({ }^{\circ} \mathrm{C}\right)$ registrada no mês de setembro às $15 \mathrm{~h}$, no período de $2011 \mathrm{e}$ 2012.

\begin{tabular}{cccccccccc}
\hline & \multicolumn{4}{c}{ Pontos no interior das FES } & \multicolumn{3}{c}{$\begin{array}{c}\text { Pontos fora das FES (áreas de } \\
\text { pastagens) }\end{array}$} \\
\hline Ano & Dia & P1 & P2 & P3 & P4 & P5 & P6 & P7 & P8 \\
\hline 2011 & 11 & 31,0 & 29,6 & 31,0 & 32,9 & 34,3 & 33,0 & 33,4 & 33,1 \\
& 12 & 32,4 & 31,0 & 32,3 & 34,2 & 36,9 & 35,3 & 35,4 & 35,3 \\
& 13 & 35,2 & 33,7 & 35,3 & 38,0 & 40,8 & 38,3 & 39,2 & 39,1 \\
& 14 & 25,2 & 26,9 & 26,9 & 28,3 & 27,8 & 27,8 & 28,9 & 29,9 \\
& 15 & 31,9 & 30,9 & 32,9 & 33,6 & 35,8 & 36,6 & 35,3 & 34,6 \\
& 16 & 30,0 & 28,7 & 30,7 & 32,4 & 35,9 & 35,2 & 35,3 & 34,5
\end{tabular}


ANÁLISE MICROCLIMÁTICA NO INTERIOR E FORA DAS FLORESTAS ESTACIONAIS SEMIDECIDUAIS NA ÁREA DA BACIA DA USINA HIDRELÉTRICA DE CAÇU-GO Andreia Medeiros de Lima e Zilda de Fátima Mariano

\begin{tabular}{|c|c|c|c|c|c|c|c|c|c|}
\hline & 17 & 31,9 & 30,7 & 32,4 & 33,6 & 36,9 & 35,2 & 37,9 & 34,8 \\
\hline & 18 & 32,2 & 31,2 & 32,8 & 34,0 & 37,7 & 35,9 & 37,2 & 34,5 \\
\hline & 19 & 31,5 & 30,2 & 31,5 & 32,7 & 36,3 & 35,2 & 36,3 & 33,5 \\
\hline & 20 & 33,8 & 32,1 & 33,7 & 35,7 & 38,7 & 38,1 & 38,4 & 37,3 \\
\hline & 21 & 34,6 & 34,0 & 35,2 & 37,6 & 37,3 & 38,1 & 37,7 & 38,0 \\
\hline & 22 & 36,1 & 35,0 & 36,4 & 39,1 & 41,2 & 39,5 & 39,5 & 40,8 \\
\hline & 23 & 36,7 & 37,6 & 37,9 & 39,6 & 38,5 & 38,7 & 40,6 & 40,5 \\
\hline & 24 & 28,0 & 27,3 & 27,7 & 29,4 & 30,6 & 30,2 & 30,2 & 30,1 \\
\hline & 25 & 30,2 & 28,8 & 30,0 & 31,6 & 33,7 & 32,4 & 33,0 & 31,9 \\
\hline & 26 & 35,2 & 33,5 & 34,0 & 37,0 & 40,8 & 37,5 & 39,2 & 38,4 \\
\hline & 27 & 34,2 & 33,5 & 33,4 & 37,6 & 39,9 & 38,1 & 37,8 & 38,8 \\
\hline & 28 & 34,9 & 34,8 & 34,9 & 38,4 & 41,3 & 38,5 & 38,6 & 40,0 \\
\hline & 29 & 35,9 & 35,1 & 35,6 & 39,2 & 42,1 & 39,3 & 40,7 & 39,4 \\
\hline & 30 & 35,7 & 35,2 & 35,5 & 38,6 & 40,2 & 39,0 & 40,3 & 39,9 \\
\hline \multirow[t]{12}{*}{2012} & 1 & 33,2 & 32,1 & 33,9 & 38,5 & 38,7 & 37,6 & 39,1 & 38,5 \\
\hline & 2 & 33,7 & 32,9 & 34,5 & 39,4 & 39,8 & 39,1 & 40,8 & 39,4 \\
\hline & 3 & 34,1 & 33,2 & 34,6 & 38,8 & 40,1 & 39,4 & 40,6 & 38,8 \\
\hline & 4 & 33,9 & 32,6 & 34,5 & 39,6 & 40,1 & 38,6 & 40,4 & 39,6 \\
\hline & 5 & 34,0 & 33,5 & 34,6 & 38,8 & 38,9 & 40,2 & 41,6 & 39,1 \\
\hline & 6 & 34,0 & 33,0 & 34,3 & 37,3 & 38,5 & 39,8 & 41,8 & 37,3 \\
\hline & 7 & 33,9 & 33,9 & 34,4 & 38,8 & 39,0 & 39,1 & 41,8 & 38,8 \\
\hline & 8 & 34,3 & 33,2 & 34,7 & 37,6 & 39,4 & 38,9 & 42,7 & 38,7 \\
\hline & 9 & 34,9 & 33,5 & 35,2 & 40,0 & 41,2 & 40,1 & 42,5 & 40,0 \\
\hline & 10 & 35,7 & 34,4 & 35,9 & 39,5 & 42,6 & 40,9 & 42,8 & 39,5 \\
\hline & 11 & 35,3 & 34,9 & 35,7 & 39,7 & 40,9 & 39,6 & 41,1 & 39,7 \\
\hline & 12 & 31,0 & 34,9 & 31,0 & 32,9 & 40,3 & 33,0 & 33,4 & 33,1 \\
\hline \multicolumn{2}{|c|}{ Valor máximo } & 36,7 & 37,6 & 37,9 & 40 & 42,6 & 40,9 & 42,8 & 40,8 \\
\hline \multicolumn{10}{|c|}{ Amplitude } \\
\hline
\end{tabular}

Fonte: Lima; Mariano (2013).

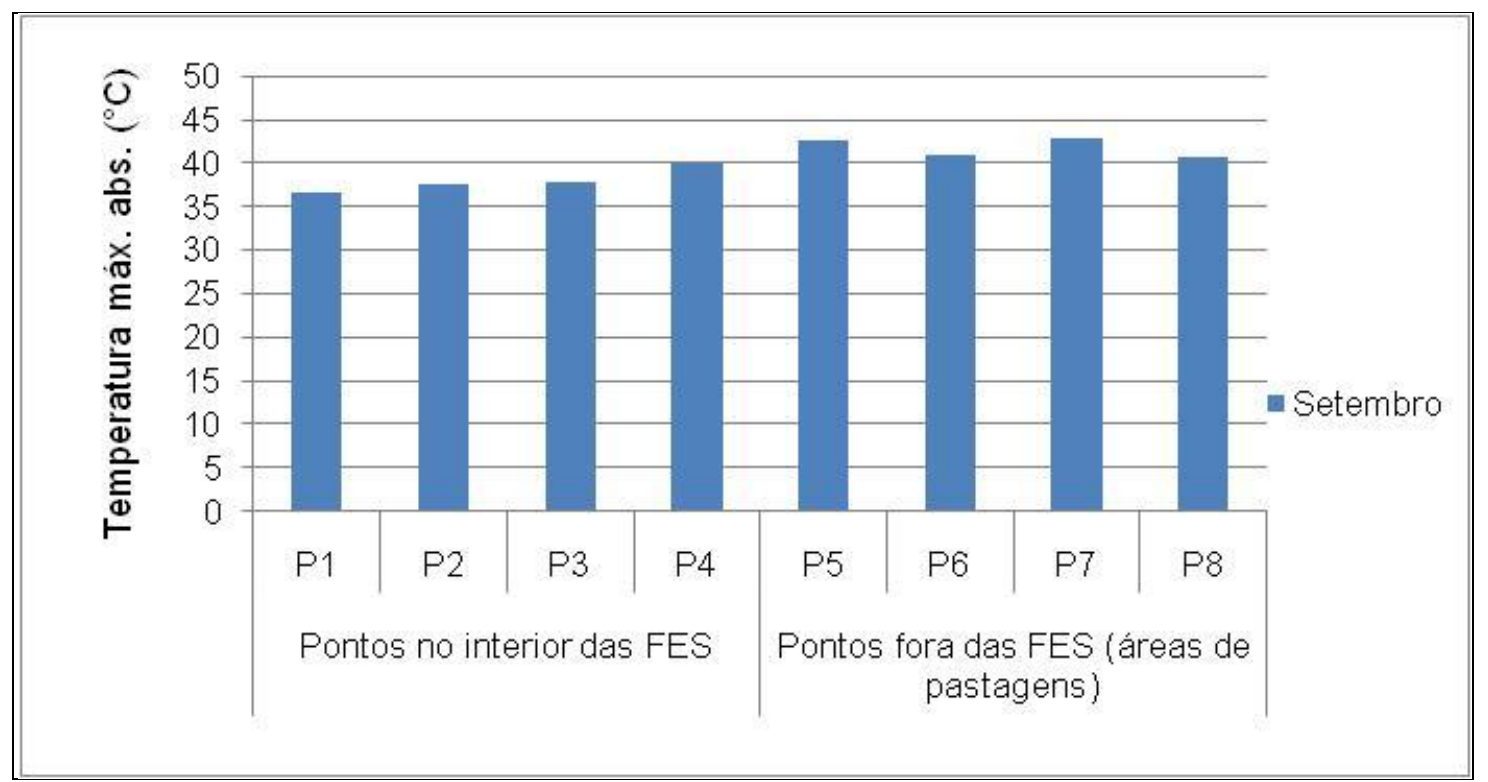

Figura 6- Variação das temperaturas máximas absolutas, nos pontos no interior e fora das FES, na Bacia Hidrelétrica de Caçu-GO, no mês de setembro de 2011 e setembro de 2012.

Org.: Lima (2013) 
$\overline{\text { As temperaturas mínimas absolutas ocorreram no mês de julho. Neste período os pontos no }}$ interior das FES estão sujeitos à perda das folhas e, consequentemente, à modificação na cobertura do dossel, associados à atuação da massa de ar Polar Atlântica, caracterizando temperaturas menores no $\mathrm{P} 1\left(4,1^{\circ} \mathrm{C}\right)$ e no $\mathrm{P} 3\left(3,8^{\circ} \mathrm{C}\right)$, no $\mathrm{P} 2$ e $\mathrm{P} 4$ foram registradas 6,6 e 5,1 oC, respectivamente (Tabela 3 e Figura 7).

Nos pontos fora das FES as menores temperaturas mínimas absolutas foram de 1 으 no P5,

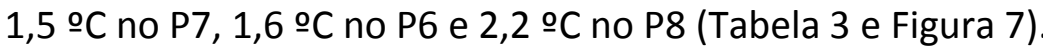

As temperaturas mínimas absolutas nos pontos dentro das FES foram maiores em comparação aos pontos fora das FES. Isto ocorre devido ao dossel vegetal que auxilia na manutenção da temperatura, a energia adentra o dossel, demora mais tempo para aquecêlo, no entanto, demora mais para dissipar, tornando o ambiente abaixo do dossel aquecido por mais tempo.

A maior diferença ocorreu entre o P5 e o P2 de 5,5 ${ }^{\circ} \mathrm{C}$, visto que o ponto P5 localiza-se em solo exposto e a $20 \mathrm{~m}$ do reservatório da UHE influenciando em menores temperaturas mínimas absolutas (Tabela 3 e Figura 7).

Tabela 3 - Temperaturas mínimas absolutas $\left({ }^{\circ} \mathrm{C}\right)$ registrada no mês de julho às 7h, no período de 2011 e 2012

\begin{tabular}{cccccccccc}
\hline & \multicolumn{4}{c}{ Pontos no interior das FES } & \multicolumn{5}{c}{ Pontos fora das FES } \\
\hline Ano & Dia & P1 & P2 & P3 & P4 & P5 & P6 & P7 & P8 \\
\hline 2012 & 1 & 13,9 & 13,8 & 24,4 & 13,9 & 10,7 & 10,9 & 11,3 & 12,2 \\
& 2 & 15,3 & 14,5 & 25,6 & 15,3 & 11,5 & 11,2 & 11,8 & 13,1 \\
& 3 & 15,3 & 14,3 & 25,8 & 15,3 & 10,8 & 10,8 & 11,3 & 12,8 \\
& 4 & 13,0 & 12,7 & 24,5 & 13,0 & 9,5 & 9,4 & 9,9 & 10,9 \\
& 5 & 13,3 & 12,8 & 18,4 & 13,3 & 9,5 & 9,5 & 9,9 & 10,9 \\
& 6 & 14,4 & 14,2 & 25,2 & 14,4 & 11,1 & 11,2 & 11,8 & 12,5 \\
& 7 & 15,0 & 14,9 & 15,0 & 15,0 & 12,6 & 12,5 & 13,0 & 13,4 \\
& 8 & 14,8 & 15,3 & 14,8 & 14,8 & 14,9 & 14,8 & 15,2 & 14,3 \\
& 9 & 11,0 & 12,7 & 11,0 & 11,0 & 11,1 & 10,6 & 10,4 & 10,6 \\
& 10 & 13,8 & 13,3 & 13,8 & 13,8 & 10,3 & 10,5 & 10,7 & 11,8 \\
& 11 & 14,1 & 14,0 & 13,4 & 14,1 & 11,1 & 12,0 & 12,3 & 12,5 \\
& 12 & 16,4 & 17,0 & 15,7 & 16,9 & 15,7 & 15,3 & 16,2 & 16,3 \\
& 13 & 14,7 & 15,6 & 15,5 & 15,1 & 15,2 & 15,8 & 16,0 & 15,0 \\
& 14 & 9,9 & 10,3 & 9,7 & 10,8 & 7,5 & 7,4 & 7,5 & 8,4 \\
& 15 & 7,8 & 9,4 & 7,6 & 9,1 & 5,2 & 5,3 & 5,5 & 6,0 \\
& 16 & 9,8 & 9,9 & 9,2 & 11,1 & 6,7 & 7,1 & 7,5 & 8,2 \\
17 & 14,4 & 14,9 & 13,8 & 14,7 & 14,2 & 13,9 & 14,8 & 14,6 \\
& 18 & 9,8 & 11,1 & 10,4 & 10,7 & 7,7 & 8,8 & 7,7 & 8,0 \\
19 & 4,1 & 7,3 & 3,8 & 5,1 & 1,0 & 1,6 & 1,5 & 2,2 \\
20 & 5,0 & 6,6 & 4,4 & 6 & 1,7 & 1,7 & 2,4 & 2,7 \\
21 & 9,5 & 9,6 & 8,9 & 9,9 & 6,8 & 7,2 & 7,6 & 7,6 \\
& 22 & 13,4 & 13,4 & 13,0 & 13,9 & 10,6 & 10,5 & 11,5 & 11,4 \\
& 23 & 17,5 & 17,5 & 17,4 & 17,7 & 15,8 & 16,7 & 17,1 & 16,7 \\
& 24 & 17,6 & 17,5 & 17,8 & 18,3 & 16,5 & 16,9 & 17,2 & 16,9 \\
& 25 & 14,0 & 14,3 & 13,7 & 15,1 & 11,3 & 11,2 & 11,8 & 11,9 \\
& 13,0 & 13,5 & 12,8 & 13,9 & 9,9 & 10,2 & 10,8 & 11,0 \\
\hline
\end{tabular}




\begin{tabular}{rcccccccc}
\hline 27 & 13,4 & 13,3 & 12,7 & 14 & 9,8 & 10,0 & 10,5 & 10,8 \\
28 & 12,6 & 12,7 & 11,8 & 13 & 9,3 & 9,9 & 10,2 & 10,0 \\
29 & 11,4 & 12,1 & 11,1 & 12,9 & 8,6 & 8,6 & 9,3 & 9,7 \\
30 & 12,4 & 13,2 & 12,2 & 13,3 & 9,3 & 9,6 & 10,2 & 10,4 \\
31 & 11,9 & 12,2 & 11,2 & 12,9 & 8,8 & 9,1 & 9,4 & 10,0 \\
\hline Valor mínimo & 4,1 & 6,6 & 3,8 & 5,1 & 1 & 1,6 & 1,5 & 2,2 \\
\hline Amplitude & & & & & & & & 14,7 \\
Térmica & 13,5 & 10,9 & 22 & 13,2 & 15,5 & 15,3 & 15,7 & 14,7 \\
\hline
\end{tabular}
Fonte: Lima; Mariano (2013).

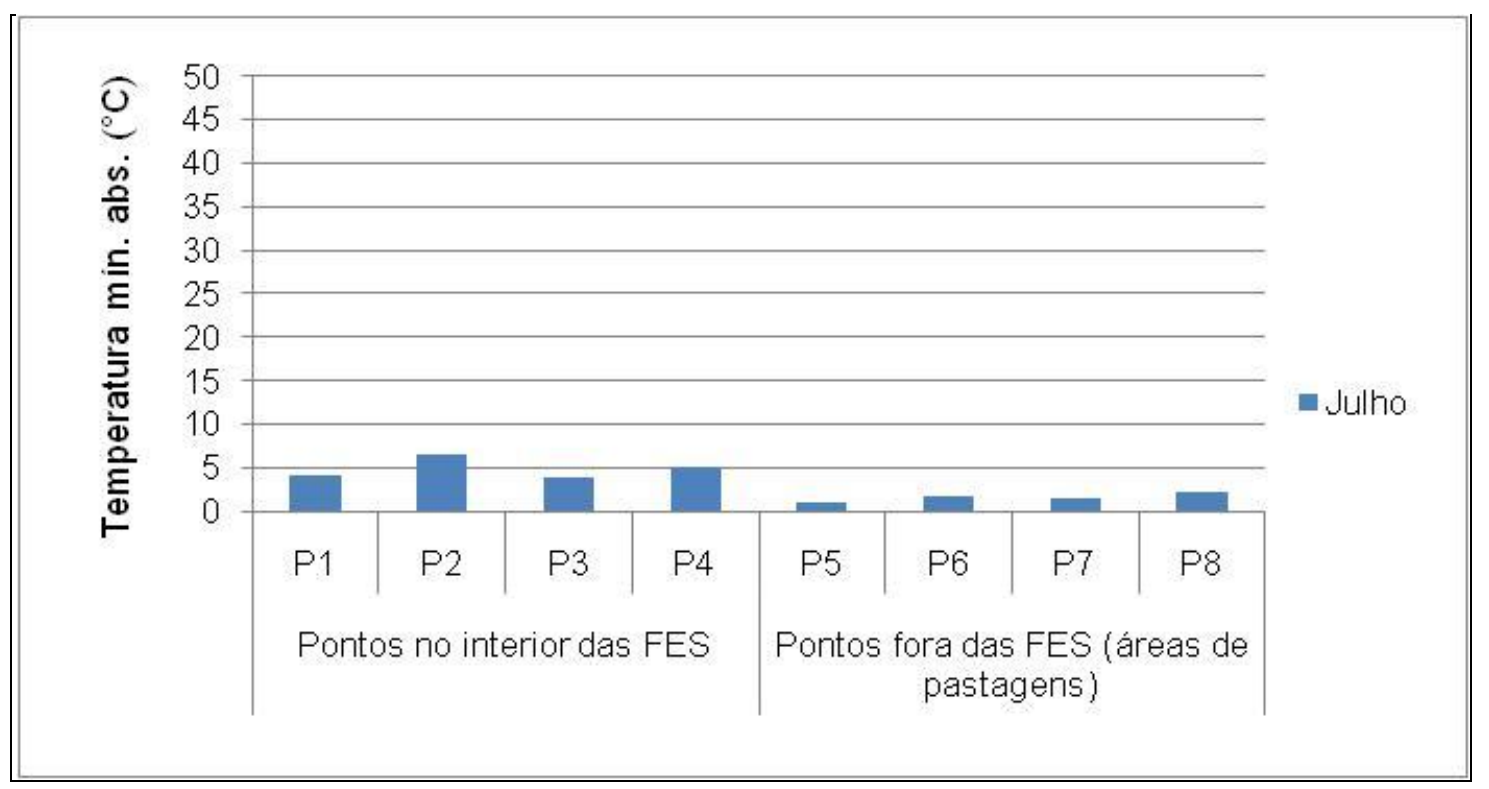

Figura 7- Variação das temperaturas mínimas absolutas, nos pontos no interior e fora das FES, na Bacia Hidrelétrica de Caçu-GO, no mês de julho de 2011 e julho 2012.

Org.: Lima (2013)

\section{Variação da umidade relativa do ar máximas e mínimas absolutas}

Os maiores valores absolutos de umidade relativa do ar ocorreram no mês de janeiro, nos pontos dentro das FES (P1, P2 e P3) com 100\% devido ao período das chuvas e, também, à presença de serrapilheira depositada no solo e à evapotranspiração que mantém a umidade abaixo do dossel e o menor valor de 97\%, no P4, (Tabela 4 e Figura 8 )

Os pontos fora das FES (P5, P6, P7 e P8) registraram os menores valores das máximas absolutas 94, 95, 96 e 97\%, respectivamente. Em relação ao ponto de referência P1, a falta de cobertura arbórea e a exposição das vertentes a noroeste e oeste levam esses ambientes a se aquecerem rapidamente e a perderem umidade. (Tabela 4 e Figura 8 )

Os menores valores de umidade mínima absoluta (Tabela 5 e Figura 9) ocorreram no mês de setembro, no $\mathrm{P} 1$, com $15 \%$, no $\mathrm{P} 2$, com $17 \%$, no $\mathrm{P} 3$, com $18 \%$ e no $\mathrm{P} 4$, com $17 \%$, período de 
estiagem que, associado às modificações na estrutura do dossel, influenciam na baixa umidade relativa do ar.

Tabela 4 - Umidade máxima absoluta (\%) registrada no mês de janeiro às 5 h, no período de 2012.

\begin{tabular}{|c|c|c|c|c|c|c|c|c|c|}
\hline \multirow[b]{2}{*}{ Ano } & \multirow[b]{2}{*}{ Dia } & \multicolumn{4}{|c|}{ Pontos no interior das FES } & \multicolumn{4}{|c|}{ Pontos fora das FES } \\
\hline & & P1 & P2 & P3 & P4 & P5 & P6 & P7 & P8 \\
\hline \multirow[t]{31}{*}{2012} & 1 & 98 & 94 & 93 & 93 & 92 & 93 & 93 & 89 \\
\hline & 2 & 99 & 94 & 99 & 95 & 93 & 93 & 94 & 91 \\
\hline & 3 & 92 & 89 & 94 & 87 & 91 & 91 & 92 & 88 \\
\hline & 4 & 91 & 87 & 94 & 88 & 90 & 90 & 89 & 86 \\
\hline & 5 & 93 & 89 & 90 & 90 & 92 & 91 & 91 & 87 \\
\hline & 6 & 95 & 88 & 92 & 92 & 93 & 93 & 93 & 90 \\
\hline & 7 & 93 & 89 & 90 & 90 & 91 & 91 & 90 & 88 \\
\hline & 8 & 95 & 94 & 93 & 93 & 92 & 92 & 91 & 89 \\
\hline & 9 & 95 & 93 & 93 & 93 & 92 & 93 & 92 & 90 \\
\hline & 10 & 97 & 96 & 93 & 93 & 91 & 93 & 93 & 90 \\
\hline & 11 & 99 & 98 & 93 & 96 & 93 & 94 & 94 & 96 \\
\hline & 12 & 99 & 99 & 96 & 96 & 93 & 94 & 94 & 96 \\
\hline & 13 & 100 & 100 & 96 & 97 & 93 & 94 & 96 & 97 \\
\hline & 14 & 100 & 100 & 95 & 95 & 93 & 94 & 94 & 95 \\
\hline & 15 & 97 & 98 & 91 & 91 & 91 & 93 & 91 & 91 \\
\hline & 16 & 99 & 100 & 95 & 95 & 93 & 94 & 94 & 95 \\
\hline & 17 & 99 & 100 & 98 & 94 & 92 & 93 & 94 & 94 \\
\hline & 18 & 100 & 100 & 98 & 96 & 94 & 94 & 95 & 96 \\
\hline & 19 & 100 & 100 & 96 & 96 & 94 & 95 & 96 & 96 \\
\hline & 20 & 100 & 100 & 92 & 95 & 93 & 93 & 94 & 95 \\
\hline & 21 & 98 & 100 & 92 & 92 & 91 & 91 & 93 & 92 \\
\hline & 22 & 98 & 99 & 94 & 94 & 91 & 92 & 93 & 94 \\
\hline & 23 & 98 & 99 & 93 & 92 & 90 & 92 & 93 & 92 \\
\hline & 24 & 100 & 99 & 95 & 95 & 91 & 92 & 92 & 95 \\
\hline & 25 & 100 & 100 & 98 & 96 & 93 & 94 & 94 & 96 \\
\hline & 26 & 100 & 100 & 98 & 96 & 93 & 93 & 95 & 96 \\
\hline & 27 & 100 & 100 & 97 & 96 & 93 & 93 & 94 & 96 \\
\hline & 28 & 100 & 100 & 96 & 95 & 94 & 94 & 95 & 95 \\
\hline & 29 & 100 & 100 & 98 & 95 & 91 & 93 & 95 & 95 \\
\hline & 30 & 99 & 99 & 97 & 93 & 92 & 94 & 94 & 93 \\
\hline & 31 & 95 & 98 & 91 & 91 & 89 & 91 & 91 & 91 \\
\hline \multicolumn{2}{|c|}{ Valor máximo } & 100 & 100 & 99 & 97 & 94 & 95 & 96 & 97 \\
\hline \multicolumn{10}{|c|}{ Amplitude } \\
\hline \multicolumn{2}{|c|}{ Térmica } & 9 & 13 & 9 & 10 & 5 & 5 & 7 & 11 \\
\hline
\end{tabular}

Os pontos localizados fora das FES (P5, P6, P7 e P8) registraram 16\%, 13\%, 13\% e $17 \%$ respectivamente. Em relação ao ponto de referência $\mathrm{P} 1$, a umidade relativa do ar mínima absoluta, mostrou relação entre a baixa umidade e o uso do solo, verificou-se valores muito baixos no P6 e P7 pontos que apresentam falta de cobertura vegetal, (Tabela 5 e Figura 9). 


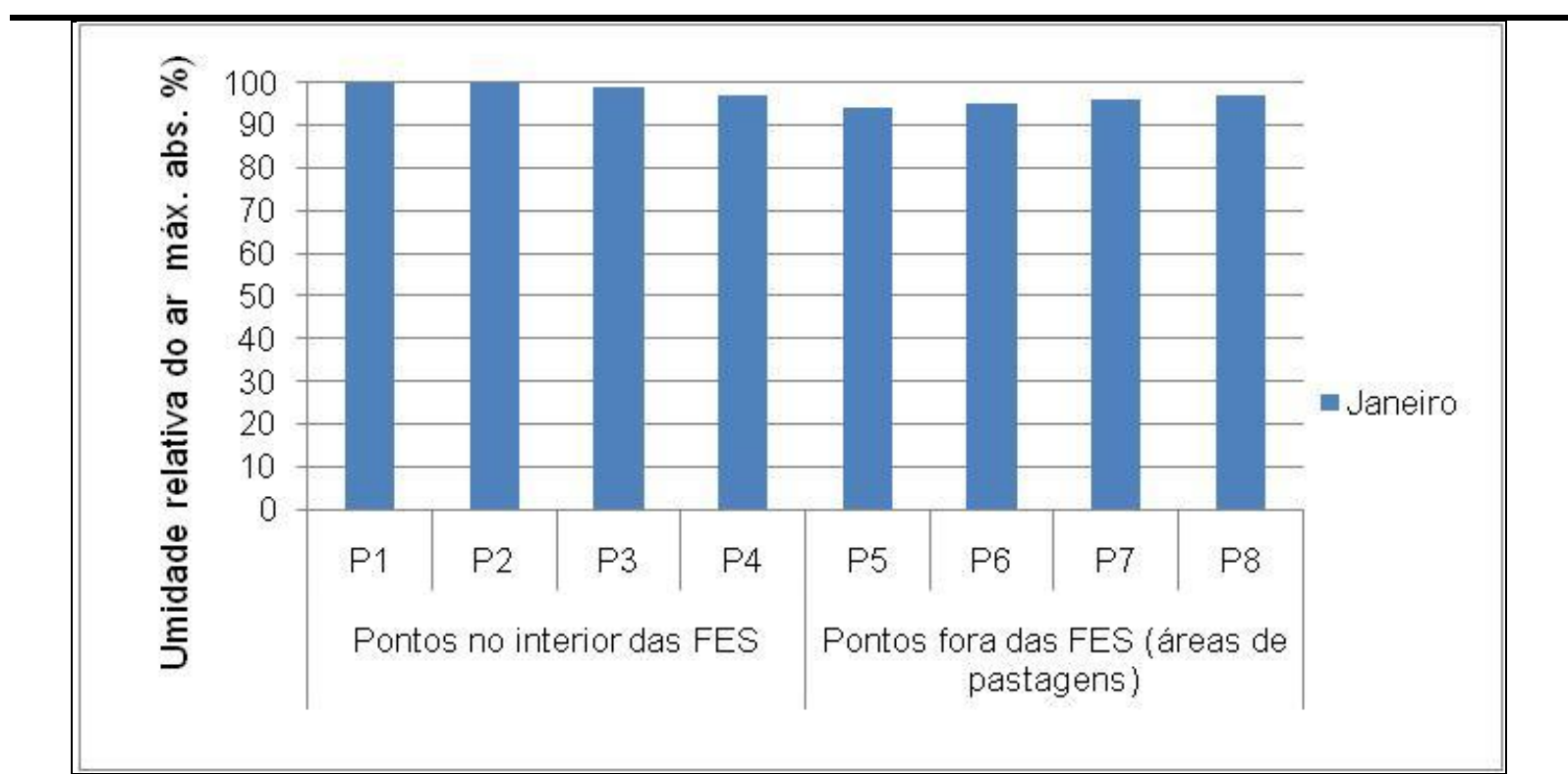

Figura 8- Variação das umidades máximas absolutas, nos pontos no interior e fora das FES, na Bacia Hidrelétrica de Caçu-GO, no período de 2012.

Org.: Lima (2013)

Tabela 5 - Umidade mínima absoluta (\%) registrada no mês de setembro às $15 \mathrm{~h}$,

\begin{tabular}{|c|c|c|c|c|c|c|c|c|c|}
\hline \multirow[b]{2}{*}{ Ano } & \multirow[b]{2}{*}{ Dia } & \multicolumn{4}{|c|}{ Pontos no interior das FES } & \multicolumn{4}{|c|}{ Pontos fora das FES } \\
\hline & & P1 & $\mathrm{P} 2$ & P3 & P4 & P5 & P6 & P7 & P8 \\
\hline \multirow[t]{20}{*}{2011} & 11 & 41 & 49 & 45 & 40 & 37 & 39 & 38 & 39 \\
\hline & 12 & 33 & 43 & 37 & 34 & 29 & 31 & 30 & 32 \\
\hline & 13 & 23 & 30 & 26 & 23 & 20 & 21 & 20 & 21 \\
\hline & 14 & 57 & 45 & 47 & 47 & 51 & 45 & 43 & 40 \\
\hline & 15 & 36 & 40 & 35 & 33 & 29 & 28 & 30 & 30 \\
\hline & 16 & 38 & 48 & 37 & 32 & 27 & 27 & 28 & 29 \\
\hline & 17 & 30 & 41 & 33 & 28 & 24 & 27 & 23 & 26 \\
\hline & 18 & 25 & 37 & 31 & 27 & 22 & 24 & 21 & 25 \\
\hline & 19 & 28 & 35 & 28 & 26 & 23 & 22 & 21 & 25 \\
\hline & 20 & 21 & 31 & 28 & 24 & 21 & 20 & 20 & 22 \\
\hline & 21 & 26 & 29 & 25 & 23 & 22 & 21 & 21 & 23 \\
\hline & 22 & 25 & 29 & 27 & 23 & 22 & 22 & 21 & 22 \\
\hline & 23 & 23 & 17 & 22 & 20 & 19 & 18 & 17 & 18 \\
\hline & 24 & 48 & 53 & 51 & 47 & 43 & 44 & 43 & 45 \\
\hline & 25 & 38 & 49 & 43 & 37 & 34 & 36 & 35 & 37 \\
\hline & 26 & 26 & 33 & 34 & 27 & 24 & 27 & 23 & 26 \\
\hline & 27 & 29 & 35 & 36 & 27 & 25 & 26 & 26 & 26 \\
\hline & 28 & 24 & 31 & 28 & 24 & 19 & 21 & 21 & 24 \\
\hline & 29 & 23 & 27 & 27 & 22 & 18 & 21 & 19 & 21 \\
\hline & 30 & 19 & 30 & 26 & 21 & 18 & 19 & 18 & 18 \\
\hline \multirow[t]{12}{*}{2012} & 1 & 21 & 30 & 24 & 22 & 21 & 19 & 18 & 22 \\
\hline & 2 & 18 & 35 & 23 & 17 & 17 & 16 & 16 & 17 \\
\hline & 3 & 19 & 34 & 24 & 22 & 20 & 18 & 16 & 22 \\
\hline & 4 & 20 & 38 & 24 & 21 & 20 & 18 & 17 & 21 \\
\hline & 5 & 19 & 24 & 23 & 19 & 19 & 16 & 16 & 18 \\
\hline & 6 & 22 & 33 & 27 & 21 & 21 & 17 & 16 & 21 \\
\hline & 7 & 20 & 23 & 25 & 19 & 21 & 18 & 17 & 19 \\
\hline & 8 & 19 & 31 & 22 & 20 & 18 & 16 & 15 & 21 \\
\hline & 9 & 18 & 30 & 19 & 17 & 16 & 15 & 13 & 17 \\
\hline & 10 & 15 & 25 & 18 & 17 & 16 & 13 & 13 & 17 \\
\hline & 11 & 20 & 25 & 22 & 21 & 20 & 18 & 16 & 21 \\
\hline & 12 & 41 & 33 & 45 & 40 & 20 & 17 & 38 & 39 \\
\hline
\end{tabular}


ANÁLISE MICROCLIMÁTICA NO INTERIOR E FORA DAS FLORESTAS ESTACIONAIS SEMIDECIDUAIS NA ÁREA DA BACIA DA USINA HIDRELÉTRICA DE CAÇU-GO Andreia Medeiros de Lima e Zilda de Fátima Mariano

\begin{tabular}{ccccccccc}
\hline Valor mínimo & 15 & 17 & 18 & 17 & 16 & 13 & 13 & 17 \\
\hline $\begin{array}{c}\text { Amplitude } \\
\text { térmica }\end{array}$ & 9 & 13 & 9 & 10 & 5 & 5 & 7 & 11 \\
\hline \multicolumn{7}{c}{ Fonte: Lima; Mariano (2013) }
\end{tabular}

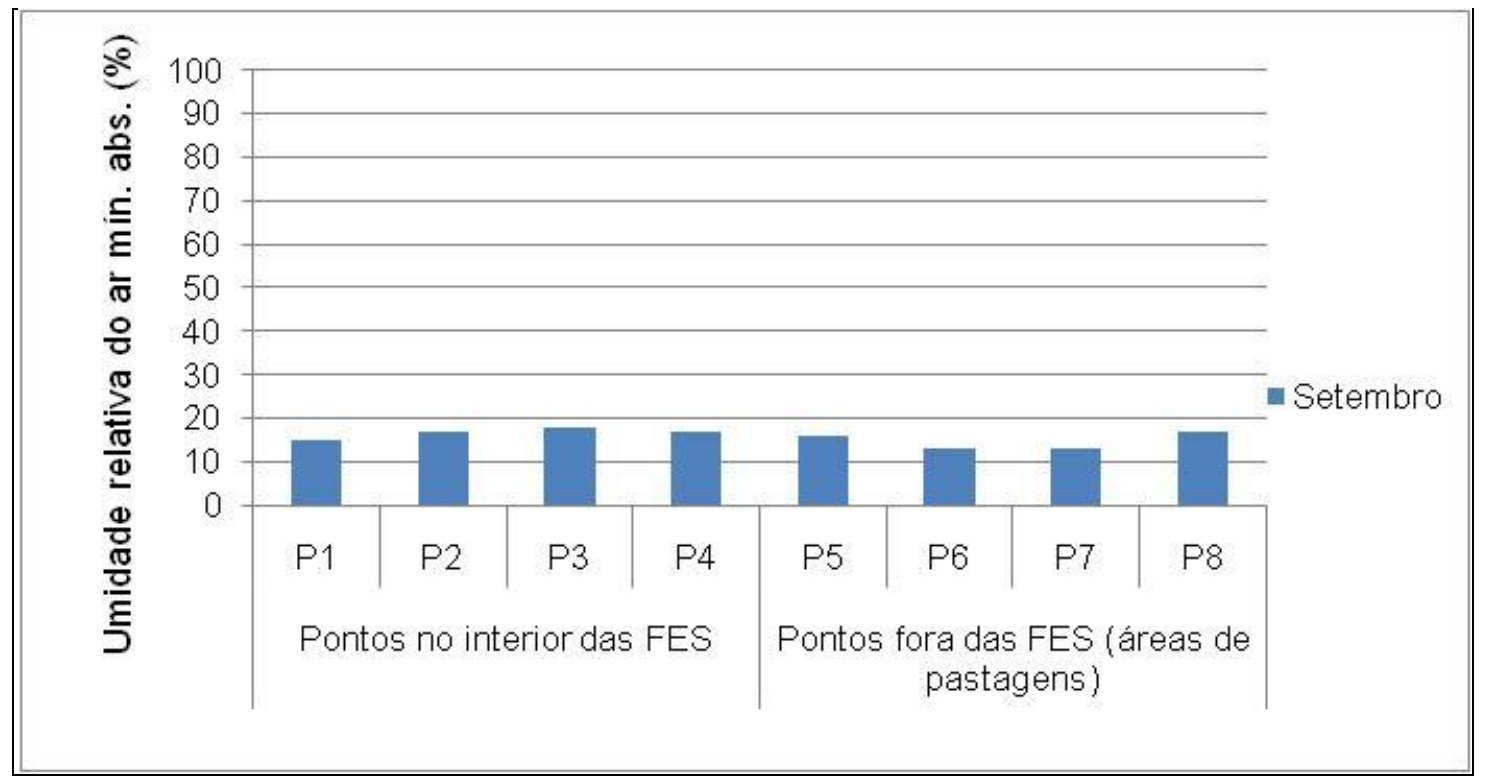

Figura 9- Variação das umidades mínimas absolutas, nos pontos no interior e fora das FES, na Bacia Hidrelétrica de Caçu-GO, em setembro de 2011 e setembro de 2012.

Org.: Lima (2013)

\section{CONCLUSÕES}

A presente pesquisa concluiu que:

$\checkmark$ O ponto no interior das FES P1 em melhor estado de conservação apresentou uma diferença de 3,3 ํC na temperatura máxima absoluta no mês de setembro em relação ao ponto P4 em menor estado de conservação;

$\checkmark$ Os pontos fora das FES, nas áreas de pastagens registraram as maiores temperaturas

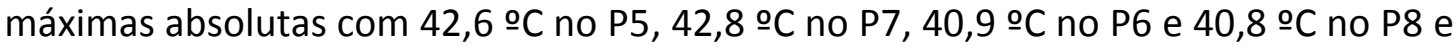

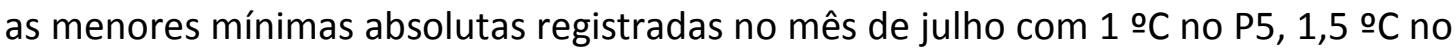
$\mathrm{P} 7,1,6 \stackrel{\circ}{\circ}$ no $\mathrm{P} 6$ e 2,2 ㅇ $\mathrm{C}$ no P8;

Em relação à umidade relativa do ar máxima absoluta nos pontos dentro das FES P1 e P2 registraram-se os maiores valores em agosto com 100\%, o P3 e o P4 registraram 99\% e 97\%, respectivamente, já a umidade mínima absoluta foi registrada no mês de setembro, com $15 \%$ no P1, $17 \%$ no P2, $18 \%$ no P3 e $17 \%$ no P4; 
$\checkmark$ A umidade máxima absoluta nos pontos fora das FES foi de $94 \%$ no P5, 95\% no P6, 96\% no P7 e 98\% no P8, no mês de janeiro e as mínimas absolutas no mês de setembro com 5\% no P5 e P6, 7\% no P7 e $11 \%$ no P8;

$\checkmark$ Os pontos no interior das Florestas Estacionais Semideciduais (FES) com melhor estado de preservação tiveram um microclima com menores temperaturas máximas absolutas, maiores temperaturas mínimas absolutas e umidade relativa do ar;

$\checkmark$ As FES (P3 e P4) com maior interferência antrópica mostraram modificações na temperatura e umidade relativa do ar, assim a estrutura da vegetação, altura, número de indivíduos, densidade absoluta provocam alterações no microclima.

$\checkmark$ O ponto de referência permitiu observar que o uso da terra provoca mudanças no ambiente adjacente, pois os pontos com predominância de pastagens registraram as maiores temperaturas máximas absolutas;

$\checkmark$ O microclima no interior das FES constitui um ambiente distinto devido ao dossel vegetal, favorecendo menor incidência da radiação solar; alta umidade relativa do ar, devido à evapotranspiração e a serrapilheira que tornam o solo mais úmido, assim a preservação das FES é de suma importância para espécies animais e vegetais dependentes desse ambiente com características microclimáticas amenas.

\section{REFERÊNCIAS BIBLIOGRÁFICAS}

ARMANI, G. Análise topo e microclimática tridimensional em uma microbacia hidrográfica de clima tropical úmido de altitude. 2009. v.1. 123f. Tese (Doutorado em geografia)Faculdade de Filosofia Letras e Ciências Humanas, Universidade de São Paulo, São Paulo, 2009.

EMBRAPA. Sistema brasileiro de classificação de solos. Centro Nacional de Pesquisa de Solos, Rio de Janeiro: EMBRAPA-SPI, 2009. Disponível em:

<http://www.solos.ufmt.br/docs/esp/SIBCs_2009.pdf >. Acesso em: 05 maio 2012.

EIBHSG- Estudo Integrado de Bacias Hidrográficas do Sudoeste Goiano, Goiânia, 2005. CDROM. 
FELFILI, J. M.; REZENDE, R. P. Conceitos e métodos em fitossociologia. Comunicações técnicas florestais, v. 5, n.1. Brasília. Universidade de Brasília, Departamento de Engenharia Florestal, 2003. 68p.

GALVANI, E. ; LIMA, Nádia Gilma Beserra de. Estudos Climáticos nas escalas inferiores do clima: manguezais da Barra do Rio Ribeira, Iguape, SP. Revista Mercator, Fortaleza, CE, v.9, n. especial 1. 2010. Disponível em: <http://www.mercator.ufc.br/index.php/ mercator/ article/view/531/296>. Acesso em: 02 maio 2012.

GEIGER, R. Manual de microclimatologia: O clima da camada de ar junto ao solo. 4 ed. Lisboa Fundação: Calouste Gulbenkian, 1961, 555p.

HERNANDES, J. L. Diferenças microclimáticas entre ambientes de interior de mata, vinhedo e posto meteorológico em Jundiaí, SP. 2001. 109 f. Dissertação (Mestrado em agricultura tropical e subtropical)- Instituto Agonômico de Campinas, Campinas-SP, 2001.

LIMA, N. G. B. Análise microclimática dos manguezais da Barra do Ribeira-Iguape/SP. 2009.185f. Dissertação de mestrado (Programa de Pós-graduação em Geografia Física)Faculdade de Filosofia, Letras e Ciências Humanas da Universidade de São Paulo, 2009.

LOPES, R. M. Análise topo e microclimática da RPPN- Pousada das Araras Serranópolis-GO. 2011. 106 f. Dissertação (Mestrado em Geografia). Universidade Federal de Goiás- Câmpus Jataí. Jataí-GO. 2011.

MARIANO, Z. de F. A importância da variável climática na produtividade de soja no sudoeste de Goiás. 2005. 253 f. Tese (Doutorado em Geografia)-Instituto de Geociências e Ciências Exatas, Campus de Rio Claro-SP, Universidade Estadual Paulista, Rio Claro-SP, 2005.

MENDONÇA, F.; DANNI-OLIVEIRA, I. M. Climatologia: concepções científicas e escalas de abordagem. In__ Climatologia: noções básicas e clima no Brasil. São Paulo: Oficina de Textos, 2007. 206 p.

MONTEIRO, M. B. C. A.; AZEVEDO, T. R. DE. Comparação do perfil vertical da temperatura e da umidade relativa do ar em fragmentos de mata Atlântica. Estudos Geográficos. Rio Claro, $\begin{array}{lllll}\text { SP. } & \text { v.3. } & \text { n.2. } & \text { Disponível }\end{array}$ <http://www.periodicos.rc.biblioteca.unesp.br/index.php/estgeo/article/view/241/197>. Acesso em: 12 maio de 2012. 
MORAGAS, W. M. Análise dos sistemas ambientais do alto rio Claro - Sudoeste de Goiás: contribuição ao planejamento e gestão. 2005. 226f. Tese (Doutorado em Geografia)-Instituto de Geociências e Ciências Exatas, Campus de Rio Claro-SP, Universidade Estadual Paulista, Rio Claro-SP, 2005.

NASCIMENTO, A. R. T.; FELFILI, J. M.; MEIRELLES, E.M. Florística e estrutura da comunidade arbórea de um remanescente de Floresta Estacional Decidual de encosta, Monte Alegre, GO, Brasil. Acta Bot. Bras., v.18, n. 3, set. 2004. Disponível em: <http://www.scielo.br/scielo.php?script=sci_arttext $\quad$ \&pid =S0102$33062004000300023 \&$ lng=pt\&nrm=iso >. acesso em 18 out. 2012

NOVELIS. EIA/RIMA UHEs Caçu e Barra dos Coqueiros. 2005. 230p.

NUNES, L. H.; LOMBARDO, M. A. A questão da variabilidade climática: uma reflexão crítica. Revista IG. São Paulo. v.16 (1/2),1995, p. 21-31. Disponível em: <http://www.igeologico.sp.gov.br/dc_revista_indice.asp>. Acesso em: 04 maio 2012.

PARDÉ, J. El microclima Del bosque. In: PESSON, P. Ecologia forestal: El bosque: clima, suelo, árboles, fauna. Madrid: Ediciones Mundi-Prensa, 1978. p. 29-46.

PEREIRA, A. R.; ANGELOCCI, L. R.; SENTEHAS, P. C. Agrometeorologia: fundamentos e aplicações práticas, Guaíba-SP: Agropecuária, 2002, 478 p.

PEZZOPANE, J. E. M. Caracterização microclimática, ecofisiológica e fitossociológica em uma floresta estacional semidecidual secundária, em Viçosa, MG. 2001. 240f. Tese (Doutorado em Ciência Florestal)-Universidade Federal de Viçosa, Viçosa-MG, 2001.

PIVELLO, V. R. Manejo de fragmentos de Cerrado: princípios para a conservação da biodiversidade. In: SCARIOT, A.; SOUSA-SILVA, J. C.; FELFILI, S. M. Cerrado: Ecologia, biodiversidade e conservação. Brasília-DF, 2005, Ministério do meio ambiente.Cap.24, p. 401-413.

RIBEIRO, J. F.; WALTER, B.M.T. 2008. As principais fitofisionomias do bioma cerrado in:Sano, S. M.; et al. Cerrado: Ecologia e flora, v I. Embrapa Cerrados. Brasília, DF: Embrapa Informação Tecnológicas. Cap.6.

SERAFINI JÚNIOR, S.; GALVANI, E.; ALVES, R. R. A escolha de um cenário de referência para a identificação de impacto climático em planos de manejo. In. SIMPÓSIO BRASILEIRO DE GEOGRAFIA FÍSICA APLICADA, 14, 2011, Dourados. Anais. 2011. CD-ROM. 
SIEG. Sistema Estadual de Estatísticas Informações Geografias de Goiás. Disponível em: <http://www.sieg.go.gov.br>. Acesso em: 20 jan. 2011.

SILVA, F. A. M. da; et al. Caracterização climática do bioma Cerrado. In: SANO, S. M.,et al

(Org). Cerrado Ecologia e Flora. Vol. 1. Brasília-DF: Embrapa Informação Tecnológica, 2008, cap. 3.

Artigo recebido em 17/05/2013.

Artigo aceito em 22/04/2014. 